\title{
El Parlamento Europeo frente al conflicto del Sahara Occidental ${ }^{1}$
}

\author{
Águeda Urruela \\ Licenciada en Ciencias Politicas y Sociología \\ Universitat Autònoma de Barcelona, 08193 Beilaterra (Barcelona). Spain
}

\section{Resumen}

En el Magreb persiste un conflicto de descolonización: Sahara Occidental. El Parlamento Europeo, a pesar de su papel como defensor de los principios democráticos, ha tardado en respaldar la causa saharaui. En el artículo se analiza la evolución y el porqué de las posiciones del Parlamenro Europeo.

Palabras clave: autodeterminación, Parlamento Europeo, política exterior europea, acuerdos de pesca, relaciones CE-Marruecos.

\section{Abstract. The European Parliament facing the Western Sahara conflict}

The long-lasting decolonisation conflict of the Western Sahara remains in the Maghreb area. The European Parliament, charnpion of democratic principles, took a long time before endorsing the saharawi cause. This article considers the whys and wherefores of the European Parliament positions and its evolution.

Key words: self-determination, European Parliament, European foreign policy, fisheries agreement, CE-Morocco bilateral relations.

\section{Sumario}

Introducción

Breve referencia al conflicto

El Parlamento Europeo en el diseño de ta política exterior

La evolución de las posiciones del Parlamento Exropeo sobre el conflicto saharaut
El Parlanento Europeo recurre ai dictamen no conforme

Conclusiones

Bibliografía

1. Este artículo sintetiza parte de la memoria de licenciatura que, bajo el título de "La Comunidad Europea frente al conflicto del Sahara Occidental" y dirigida por Esther Barbé, fue presentada en la Facultat de Ciències Polf́riques i de Sociologia de la Universitat Autònoma de Barcelona en febrero de 1994. 


\section{Introducción}

El Magreb deberá en el futuro hallar una salida a un conflicto de descolonización no resuelto: Sahara Occidental. Treinta años después de haber sido reconocido el derecho de autodeterminación y veinte desde que lo confirmara el Tribural Internacional de Justicia de la Haya, el referéndum sigue aplazado. El conflicto saharaui es un obstáculo para la estabilidad de la regíon magrebí vinculada a la Comunidad Europea desde los tratados fundacionales. La propia Comunidad Europea ha definido el Magreb como área de interés prioritario, tanto en términos de seguridad como de influencia polftico-económica ${ }^{2}$. Durante los primeros años de guerra, los Estados miembros evitaron pronunciarse sobre el Sahara: «los Nueve no han evocado nunca entre ellos la cuestión del Sahara antiguamente español, cuestión que, sin embargo, debería interesarles tanto por la proximidad de este foco de tensión como por la perspectiva de una futura adhesión de España" (Schoutheete, 1980: 125). Los Nueve se proclamaron neutrales ${ }^{3}$ en un conflicto que calificaron de ámbito africano y ajeno a Europa, de esta forma sortearon un asunto critico en la agenda exterior europea debido a los intereses franceses en Marruecos. No se producirá ninguna declaración oficial de los estados miembros hasta después de que se logre un primer acuerdo de paz entre el Frente Polisario y Marruecos en 1988. Entonces los Doce adoptaron una declaración común de apoyo a la celebración de un referéndum en el marco de Naciones Unidas ${ }^{4}$, actitud que podemos calificar de mera "diplomacia declaratoria». Hay que puntualizar que solo España, Grecia e Irlanda votaron a favor de la celebración del referéndum en la Asamblea General de Naciones Unidas, mientras el resto de los países miembros se abstuvo. Con todo, esta posición común adoptada se consolidaría en la Declaración de Luxemburgo de 1991, en la que los Doce "confirman su firme apoyo al secretario general de las Naciones Unidas en sus esfuerzos en las fases finales de su plans's.

¿Qué papel ha jugado el Parlamento Europeo? En estas páginas revisaremos la trayectoria del Parlamento Europeo respecto al conflicto del Sahara Occidental. Analizaremos la actitud del Parlamento Europeo en tanto que "conciencia democrática" de la Comunidad y por su destacado papel en la defensa de los derechos humanos y de los principios democráticos. El análisis abarca los años que transcurren desde el inicio del conflicto en 1975 hasta marzo de 1993, con especial atención al período que se inicia en 1986 con la adhesión de España a la Comunidad Europea.

2. Definición contenida en Bulletin des Communautés Européennes, 12-1989, punto 1.1.15.

3. Véase sobre este particular el $7 O$ núm. C 276, de 22.11.1976, p. 4.

4. Declaración recogida en CPE. European Political Cooperation Documentation Bulletin doc. núm. 88/250.

5. Véase la declaración completa en Bol CE, 5-1991, punto 1.4.6. 


\section{Breve referencia al conflicto}

España abandonó el Sahara en febrero de 1976, los Acuerdos Tripartitos de Madrid, firmados meses antes, dejaban el territorio en manos de Marruecos y Mauritania. Un territorio, de $284.000 \mathrm{~km}^{2}$ de extensión y con dos importantes fuentes de recursos: los fosfatos y el banco de pesca ${ }^{6}$, sobre el que se había pronunciado el Tribunal Internacional de la Haya, dejando sentado que no existía ningún lazo de soberanía territorial ni con Marruecos ni con Mauritania. Sin embargo, en Marruecos, tanto la opinión pública como la práctica totalidad de las fuerzas políticas corsideran que el territorio del Sahara Occidental forma parte del antiguo imperio del Gran Magreb.

El mismo día en que los españoles abandonaron el Sahara Occidental, el Frente Polisario ${ }^{7}$ proclamó la República Árabe Saharaui Democrática (RASD). Alineado con el radicalismo revolucionario, el Frente Polisario encontró el apoyo diplomático, militar y territorial de Argelia (cuyo reconocimiento de la RASD supuso la ruptura de relaciones diplomáticas con Marruecos en marzo de 1976). A finales de la década de los setenta y principios de la década de los ochenta, el Frente Polisario también recibió ayuda de Libia hasta la firma, en 1984, del Tratado de Uxda ${ }^{8}$ entre el coronel Gadafft y el rey Hassán II. El Frente Polisario también ha sido apoyado por los Estados progresistas de la Organización de la Unidad Africana, organización en la que fue admitida como miembro la RASD en julio de 1980, del Grupo de los No Alineados, y de las Naciones Unidas. Marruecos, por su parte, contó con el favor de los Estados árabes conservadores, especialmente de Arabia Saudita, país que ha jugado un papel mediador entre los estados magrebíes. Con mucho, la mejor baza marroquí ha sido su papel como aliado de Occidente en la región magrebí. No podemos olvidar que Marruecos es un aliado de los Estados Unidos descle la independencia, y, además, el inicio de la guerra del Sahara coincide con factores externos que revalorizan el papel marroquí en el esquema estratégico norteamericano, nos réerimos a la crisis de Oriente Medio, la revolución portuguesa y, más adelante, la revolución en Irán. Este valor estratégico se ha traducido en ayuda de las sucesivas administraciones norteamericanas, entre las que destacan por su firmeza las administraciones de los presidentes Nixon y Reagan. Sin embargo, podemos afirmar que en el conflicto del Sahara Occidental predomina la dinámica regional frente a las implicaciones de la guerra fría que deben ser consideradas secundarias (Osterud, 1989). En efecto, la URSS, condicionada por los intereses económicos con el reino

6. Fl banco de pesca está considerado como uno de los más importantes del mundo, con más de $150.000 \mathrm{~km}^{2}$ de extension.

7. Denominación que corresponde al Frente Popular para ta Liberación de Saguia el Hamra y Río de Oro, movimiento de liberación nacional saharaui surgido de la lucha anticolonial contra Espafia que celebro su congreso constituyente el 10 de mayo de 1973.

8. El tratado de Uxda entre Martuecos y Libia, firmado el 13 agosto de 1984, instituyó la Unión Árabo-africana (UAA), por el que Libia se comprometió a cesar su ayuda al Polisario a cambio de que Marruecos no interfiriese en la política libia en Chad. 
alauita ${ }^{9}$, se mantuvo en el nivel básico del compromiso diplomático: afirmación del derecho de autodeterminación del pueblo saharaui reflejada en las votaciones ante Naciones Unidas, pero no llegó a reconocer a la RASD.

Ha sido en el campo diplomático donde el Frente Polisatio ha obterido sus mayores éxitos: el reconocimiento de la RASD por más de 70 países y el respaldo de importantes organizaciones internacionales. En el plano militar, en cambio, la guerra se salda con la ocupación marroquí de la totalidad del territorio ${ }^{10}$ gracias a la estrategia de los muros defensivos que se erigen en la década de los ochenta a lo largo de toda la frontera. Muros que han obligado al Frente Polisario a replegarse a Argelia, donde viven los sahatauis en campamentos de refugiados cerca de la ciudad de Tinduf (unas 150.000 personas). La ocupación del territorio, libre de los ataques de los raids polisarios, ha permitido al monarca alauita proseguir la integración del Sahara Occidental en Marruecos, tanto en términos humanos como económicos (se estima que se han trasladado al Sahara Occidental unos cien mil civiles marroquíes y un número igual de militates). El objetivo de dicha política es presentar al mundo una situación irreversible de faits accomplis.

En la segunda mitad de la década de los ochenta, en medio de la distensión en el contexto internacional, se producen una serie de acercamientos intramagrebíes que culminarán en el Tratado de la Unión del Magreb Árabe. Esto va a significar "sacrificar" la causa saharaui a los intereses de la reconciliación (Lescaut, 1988: 70) o, dicho de otro modo, poner el contencioso entre paréntesis y dejar que siga su curso en Naciones Unidas (Soudan, 1988: 18). Así, el clima creado por la reconciliación entre Argel y Rabat propició que el 30 de agosto de 1988, el Polisario y Marruecos aprobaran las propuestas presentadas por el secretario general de Naciones Unidas, Pérez de Cuéllar. El plan Pérez de Cuéllar para el Sahara Occidental quedó definitivamente aprobado por el Consejo de Seguridad en su resolución 690, de 26 de abril de 1991. Este plan establece un perfodo de 16 semanas para la aplicación del cese el fuego y 11 semanas más para la retirada de tropas marroquíes, así como el envío de la Misión de Naciones Unidas para el Referéndum del Sahara Occidental (MINURSO) encargada de la supervisión del registro de votantes, de la campaña electoral y de la votación, basada en el censo elaborado por las autoridades españolas en 1974, prevista para enero de 1992. Sin embargo, no ha sido posible aplicar el Plan en sut totalidad. Hasta el presente la MINURSO se ha semidesplegado en el territorio, a la espera de que se desbloqueen las negociaciones entre las partes sobre la definición de las personas con derecho a voto.

9. La URSS dependía de los fosfaros y de los caladeros marroquies y era, además, el principal comprador de los productos agrios de Marruecos.

10. Mauritania se retiró del territorio y firmó la paz en agosto de 1979, la economía mauritana no resistía una guerra a la que había Ilegado a dedicar el $60 \%$ del presupuesto nacional. Con esta tetirada se produjo un realineamiento regional: restablece relaciones con Argelia (13 de agosto de 1979), se adhiere al Tratado de Frazernidad y Concordia firmado por Argelia y Túnez (13 de diciembre de 1983), y reconoce a la República Árabe Saharaui Democrática (febrero de 1984). 
Marruecos pretende que la Comisión de Identificación, encatgada de revisar y actualizar el censo de 1974, incluya en dicho censo a personas de origen saharaui que abandonaron el territorio antes de 1974, la mayoría de las cuales se trasladó a Marruecos (suponen unos 120.000 votantes potenciales). A tal efecto pretende igualmente que se admitan todo tipo de documentos oficiales y, en su defecto, el testimonio oral. Posición que no acepta el Frente Polisario, que tan sólo admite documentos de identidad expedidos por las autoridades españolas en el territorio y de ninguna otra fuente, y acepta el testimonio oral para certificar la identidad en casos muy específicos. En vísperas del fin de su mandato, Pérez de Cuéllar elaboró un informe favorable a las pretensiones marroquíes ${ }^{11}$, sin embargo, el actual secretario Butros Gahli ha continuado las negociaciones para llegar a un acuerdo.

\section{El Parlamento Europeo en el diseño de la política exterior}

El déficit democrático de que adolece la Europa comunitaria es también evidente en lo que se refiere al diseño de la política exterior. El Acta Única Europea (AUE) asoció el Parlamento Europeo a los trabajos de la Cooperación Política Europea. La presidencia en ejercicio debe informar regularmente al PE sobre los temas de polftica exterior examinados en la Cooperación Política y debe velar para que los puntos de vista del $\mathrm{PE}$ sean tenidos en cuenta según el artículo 30 párrafo 4 del AUE, lo que lleva a algunos autores a opinar que confiere al Parlamento Europeo un importinte droit de regard sobre la definición, ejecución y control de la cooperación europea en materia de política exterior (Dossiers, 1988: 33). Si bien es el Consejo Europeo el que define los principios y las orientaciones generales de la política exterior y de seguridad común.

Los instrumentos de que dispone el PE para influir en la dimensión exterior de los Doce son tres: las resoluciones, las preguntas en el marco de la CPE y el dictamen conforme en acuerdos de asociación y adhesión.

a) Las resoluciones, muchas de ellas dirigidas a los ministros de Asuntos Exteriores en el marco CPE, constituyen una vía fundamental de expresión del PE que Covillers (1989: 32) equipara al rango de las declaraciones de la cooperación europea, pues reflejan, al mismo título que las declaraciones del Consejo europeo o de los ministros de Asuntos Exteriores, la voz de Europa en la escena internacional.

b) El derecho de hacer preguntas orales y escritas se utiliza como instrumento de control y de información en las cuestiones de Cooperación Política, por encima de grupos o nacionalidades, posee un marcado carácter indi-

11. Esta actitud de Pérez de Cuellar tuvo como consecuencia la dimisión del representante especjal de Naciones Unidas en el Sahara Occidental, Johannes Manz, quien además denuncib la transferencia por parte marroquí de personas no identiftcadas al interior del territorio saharaui que ha sido calificada de "segunda Marcha Verden. Véase a este respecto el artículo de M. De Froberville, «Sahara Occidental: échec au plan de paixn. Le Monde Diplomatique, noviembre de 1992, p. 13. 
vidual (Chauchat, 1989: 43-44). Sin embargo, su eficacia depende de la cooperación del interrogado, y en este sentido la práctica del Consejo no ha respondido a las expectaciones creadas por su sumisión al procedimiento de preguntas (Weiler, 1982: 26).

c) El dictamen conforme de la mayoría de los miembros del PE para que el Consejo pueda concluir acuerdos de asociación y adhesión es el único medio por el que el Parlamento puede tener un impacto efectivo en las relaciones exteriores. El PE ha utilizado este instrumento, que puede retrasar o impedir la conclusión de un acuerdo internacional, con el fin de protestar en favor del respeto de la legalidad democrática, de los derechos humanos y de los derechos de los pueblos.

El Tratado de la Unión Europea (TUE) de 1992 ha venido a confirmar el papel del Parlamento Europeo en el diseño de la política exterior y de seguridad común (Título V del TUE artículos J7 y J8). Así, de Las relaciones del Parlamento con la Comisión y el Consejo, que se entablecen en los artículos $189 \mathrm{~B}$ y $189 \mathrm{C}$, destacamos el mecanismo que permite al PE rechazar un tratado comercial o de asociación y que Tamames califica de «auténtico dispositivo de colegislación» (Tamames, 1994: 89).

\section{La evolución de las posiciones del Parlamento Europeo sobre el conflicto saharaui}

En el periodo estudiado existen 18 resoluciones que afectan a la cuestión saharaui, la mayoría de las cuales tiene su origen en la iniciativa parlamentaria, dos de la Asamblea Paritaria ACP-CE y las demás provienen de un informe de la Comisión (parlamentaria) de Asuntos Políticos, de un dictámen de la Comisión de Cooperación y Desarrollo, de una comunicación de la Comisión al Consejo y de una pregunta oral con debate. Las propuestas que nacen de la iniciativa parlamentaria provienen de los grupos Socialista y Comunista. En cuanto a las preguntas, contabilizan un total de 29, repartidas entre diputados de los grupos Socialista (17), Verdes (5), Comunista (3), Coalición de Izquierdas (2), Arco Iris (1) y Demócrata Europeo (1). Por nacionalidad, los más asiduos a la hora de formular preguntas son los españoles, seguidos de los belgas, los franceses y los británicos. Destaca la ausencia de preguntas por parte griega a pesar de que este país mantiene una política prosaharaui en Naciones Unidas desde 1975.

La primera constatación que realizamos es la ausencia de todo posicionamiento entre 1975, año en que estalla la lucha, y 1981, año en el que por primera vez el PE se pronuncia a través de la resolución sobre el Sahara Occidental de 12 de marzo de 1981. Resulta sorprendente que la Asamblea de Estrasburgo no hubiese debatido antes sobre un conflicto que implicaba la violación del derecho de los pueblos a la autodeterminación. Sin embargo, no lo es tanto si tenemos en cuenta que la resolución de 1981 es de signo claramente pro-marroquí. Habrá que esperar hasta 1989 para que el $\mathrm{PE}$ vuelva a emitir una resolu- 
ción de significación política: la resolución sobre la situación politica en el Sahara Occidental de 15 de marzo de 1989. Esta vez, el Parlamento Europeo reconoce el derecho de autodeterminación saharaui.

Si atendemos a la resolución de 1981, se constata que el PE no reconoce la existencia del Frente Polisario y considera que se trata de un conflicto de índole regional: una pugna por la hegemonía en la zona entre Marruecos, Argelia y, en segundo plano, Libia. De ahí que el PE solicite a los gobiernos de los Estados miembros que lleven a cabo una mediación entre las partes en conflicto: Marruecos y Argelia. En esos momentos Marruecos es visto como conservador aliado de Occidente y el Polisario como radical, apoyado por Argelia y Libia. Razón por la que una asamblea dominada por una mayoría relativamente sólida de derechas aprobó un texto pro-marroquí, con el voto en contra de socialistas y comunistas. La actitud del PE reflejaba la posición francesa ante el conflicto. En efecto, al principio Francia consideraba el problema del Sahara Occidental como un enfrentamiento Argelia-Marruecos, ignoraba al Polisario y proporcionaba ayuda militar a Marruecos. Sólo en 1979, tras el golpe en Mauritania, el gobierno de Giscard d'Estaing, en un intento de mejorar sus maltrechas relaciones con Argelia, reconoció el derecho a la autodeterminación del pueblo saharaui. Posición que no ha sostenido nunca en Naciones Unidas y, de hecho, ante la perspectiva de la ampliación comunitaria a España y Portugal, Francia se comprometió con Marruecos a constituirse en el abanderado de los intereses marroquies en Europa. Con el gobierno socialista francés las relaciones con Marruecos atravesaron períodos bajos, como la suspensión temporal de envío de armas en marzo de 1982 o el apoyo del presidente Mitterrand al referéndum ante el Parlamento de Rabat, en enero de 1983. Sin embargo, Francia ha continuado absteniéndose en las resoluciones de Naciones Unidas favorables al referéndum. Además, a partir de 1992, las relaciones Francia-Marruecos conocen un nuevo ímpetu (Keesing's, 1992: 39215). El norte de África es una región clave en la política exterior de Francia, que considera peligrosa la desestabilización de Marruecos si el referéndum es contrario a Hassan, por lo que no ha dudado en defender las tesis marroquíes sobre la ampliación del censo en el Consejo de Seguridad.

Entre 1981 y 1986 de nuevo se produce el silencio en la Asamblea europea, roto sólo por alguna pregunta parlamentaria aislada. Tras las elecciones de 1984 y las ampliaciones a España y Portugal el equilibrio de fuerzas en el Parlamento Europeo varía: el grupo Socialista pasa a ser el más numeroso y, dentro de éste, los diputados españoles. El primer efecto de la incorporación de parlamentarios españoles es la creación del grupo «Paz para el pueblo saharaui» que aúna voces antes dispersas y promuteve una toma de posición del PE, manteniendo vivo el interés por el tema en la Asamblea. Este grupo se reúne una vez al mes y está compuesto por diputados franceses, alemanes y sobre todo españoles, en su mayoría del Grupo Socialista, aunque también de los Verdes, de Izquierda Unida y algún liberal.

Es necesario hacer aquí un pequeño inciso para recordar la política española en relación con el conflicto saharaui. Los sucesivos gobiernos de la demo- 
cracia española han amparado su política en la carta que el gobierno español remitió a Naciones Unidas el 26 de febrero de 1976, en la que renunciaba a toda responsabilidad sobre el territorio y afirmaba que la descolonización culminaría cuando la opinión de la población "se haya expresado válidamente». Por otra parte, Marruecos y Magreb son áreas de prioridad en la agenda diplomática, tanto en términos de seguridad como económicos. La construcción de unas sólidas relaciones con Marruecos no ha impedido que simultáneamente España mantenga que el problema del Sahara Occidental es de descolonización y que sólo puede llegar a una solución mediante referéndum de autodeterminacion. Posición que defiende activamente en Naciones Unidas y a nivel de declaraciones. Para Madrid la estabilidad en la región pasa por encontrar una solución "que salvaguarde los intereses esenciales de todas las partes en el conflicton (Morán, 1984: 16).

A partir de 1986 el tema vuelve al PE en resoluciones que abarcan cuestiones como las relaciones con el Mediterráneo, la ayuda a los refugiados o las violaciones de los derechos humanos. A la vez, aumenta el número de preguntas parlamentarias, que se establece entre las cuatro o seis anuales ${ }^{12}$. En la Comunicación relativa a la Comunidad y el Mediterráneo, de 18 de abril de 1986, se incluye por primera vez en un documento parlamentario sobre el Mediterráneo una referencia al Sahara Occidental en la que se afirma que la Comunidad Europea debe favorecer soluciones pacíficas en conflictos intrarregionales. En esta misma línea, la resolución sobre ayuda a los refugiados $y$ expatriados de los paises en desarrollo, de 19 de febrero de 1987, incluye también por vez primera a los saharauis y reconoce que la CE y los Estados miembros tienen una especial responsabilidad en la búsqueda de soluciones para los refugiados saharauis debido a los vínculos diplomáticos y militares que les unen a estos pueblos. Otras tres resoluciones de 1987 condenan las violaciones de los derechos humanos cometidas por Marruecos sobre personas saharauis ${ }^{13}$.

La timidez de estas referencias contrasta con la resolución que se aprueba en la Asamblea Paritaria ACP-CE ${ }^{14}$ en septiembre de ese mismo año, 1987.

12. Hay que señalar que el porcentaje de preguntas dirigidas a los ministros reunidos en eI marco CPE es bajo. Chauchat (1989: 42-44) constata que en 1987 hubo 330 preguntas, lo que representa un $7,9 \%$ del rotal. De estas 330 preguntas, hubo 5 sobre el tema del Sahara Occidental.

13. Veanse, a este respecto, las resoluciones sobre los derechos bumanos en Marruecos y sobre la sueyte de la familia del general Oukfir y de centenares de desaparecidos en Marruecos, ambas deI 14 de mayo de 1987, en $D O$ núm. C 156, de 15.6.1987, p. 145-146; así como la resolución sobre los derechos humanos en Marruecos, de 29 de octubre de 1987, en $D O$ núm, C 318, de 30.11.1987, p. 112.

14. La Asamblea Paritaria ACP-CE quedó constituida en 1985, en el artículo 25 de los actuerdos Lomé III. Ia Asamblea está compuesta por un número igual de parlamentarios europeos y parlamentarios —o, en stu defecto, personas designadas por el gobierno- de los patses ACP. Se trata de un órgano consultivo cuyo objetivo es ptomovet la comprensión entre los pueblos que representa y apoyar un desarrollo solidario, suscita investigaciones e iniciativas, formula propuestas para la mejora de la cooperación ACP-CE, adopta resoluciones y somete sus conclusiones al Consejo de Ministros. 
En ella se establece que se trata de un problema de descolonización, se reconoce el derecho a la autodeterminación e independencia del Sahara Occidental y se piden negociaciones entre el Frente Polisario y el Reino de Marruecos. Contra lo que pudiera pensarse, la propuesta de resolución no fue presentada por parlamentarios africanos sino por los diputados europeos Simons, del Grupo Socialista, y Saby, del Grupo Comunista.

Finalmente, en 1989 el Parlamento Europeo aprueba una resolución en la que se reconoce el derecho a la autodeterminación del pueblo saharaui. EI origen de dicha resolución es una propuesta presentada por el parlamentario español, Robles Piquer, "sobre la inrensificación de la lucha armada en el Sahara Occidental y los sufrimientos de la población" que va a dar lugat al informe Christiansen elaborado por la Comisión de Asuntos Políticos (CAP) durante el año 1988. En aquella propuesta el diputado español miembro del grupo popular europeo, además de justificar la actuación española, pedía el apoyo comunitario al referéndum a la vez que el respeto a los intereses marroquíes. El informe de la CAP dio lugar a una resolución en la que se reconoce el derecho a la autodeterminación y se solicita a los Estados miembros y a la comunidad que utilicen "toda su influencia con el fin de fomentar las condiciones necesarias para la organización de la consultan. Igualmente se pide que se promuevan las negociaciones entre las partes, que la CPE desarrolle todos sus esfuerzos para expresar una posición común en el marco de la cooperación política y que dicha posición común se refleje en conferencias $\mathrm{y}$ organismos internacionales.

Por otra parte, y en lo que respecta a las preguntas parlamentarias, éstas revelan el seguimiento de los acontecimientos por parte de algunos diputados. En este caso, más que un instrumento de información son un medio de presionar a los ministros y obligarles a pronunciarse para que se ejerza una acción diplomática. La mayoría de dichas preguntas plantea la necesidad de que la Comunidad Europea tome alguna iniciativa de acuerdo con las decisiones de Naciones Unidas (negociaciones y consulta popular). Otro tema, objeto de preguntas, es la violación de los derechos humanos por parte de Marruecos. En este caso, las denuncias de los diputados, sustentadas en informes de Amnistía Internacional y de la Cruz Roja, tienen por objetivo presionar al Consejo de Ministros reunido en el marco CPE para que intervenga ante las autoridades marroquíes. Existen preguntas más comprometedoras, como las que versan sobre la venta de armas a Marruecos por parte de Estados miembros que userán utilizadas para combatir al Frente Polisario en su lucha por liberar el Sahara Occidental" 15 . Otras preguntas, también comprometedoras, son las que solicitan una explicación sobre las diferencias de voto en Naciones Unidas por parte de los europeos en relación con el tema del referéndum, así como las que denuncian que la ayuda comunitaria a Marruecos pone en entredicho la neu-

15. Pregunta del diputado español Pacheco Herrera que se recoge en EPC Documentation Bull, doc. núm. 89/288. Véase sobre el rnismo tema la pregunta que formula el diputado Kuijpers, EPC Documentation Bull, doc. núm. 87/294. 
tralidad europea en el conflicto y que en el fondo se está favoreciendo a una de las partes ${ }^{16}$.

Por último, los diputados denuncian el tratado de pesca CE-Marruecos, que supone un reconocimiento implícito de la soberanía marroquí sobre aguas saharauis. Cabe recordar aquí que los acuerdos de pesca con Marruecos, que ha negociado la Comisión dentro de la Política de Pesca Común, reconocen implicitamente en su texto la soberanía marroquí sobre aguas saharauis al referirse a ellas como «aguas sometidas a la soberanía o a la jurisdicción del Reino de Marruecos" ${ }^{17}$. Para Hassan este reconocimiento supuso un éxito diplomático, mientras que el representante del Polisario en Europa, Sr. Mohamed Sidati, lo consideró una negación de los derechos de soberanía de la RASD. El Frente Polisario, ante la actitud europea, lanzó la amenaza a los barcos comunitarios de que "no es seguro faenar en aguas saharauis". Es necesario recordar que en diciembre de 1987 el Frente Polisario había ofrecido a la CE la posibilidad de firmar un acuerdo de pesca propio para legitimar la pesca en aguas saharauis ${ }^{18}$, oferta que no tuvo respuesta por parte comunitaria. De todas maneras, Marruecos dejó al Polisario sin salida al mar gracias a la construcción del sexto muro defensivo.

A pesar de que los parlamentarios no siempre obtienen respuestas satisfactorias, podemos afirmar que dichas respuestas constituyen un "termómetro" de la disposición de los Doce frente a la cuestión saharaui. Hasta 1988 las respuestas de la presidencia remiten la solución del conflicto a Naciones Unidas, a la vez que llaman a las partes a responder a los esfuerzos del secretario general. A partir de esa fecha las respuestas pasan a expresar el apoyo de los Doce a la celebración del referéndum, y desde 1989 añaden la necesidad de que la UMA favorezca una solución del conflicto. Las respuestas revelan la negativa a vincular cuestiones del ámbito comunitario y de cooperación política; en concreto, se niegan a abordar el acuerdo de pesca y el acuerdo de libre comercio con Marruecos. Igualmente, cuestiones como el suministro de armas, las detenciones practicadas por Marruecos durante la visita de una delegación de la ONU o la anexión de las aguas saharauis mediante la construcción del sexto muro, se quedan sin contestar.

La evolución del Parlamento Europeo desde tesis pro-marroquíes hasta el reconocimiento del derecho a la autodeterminación se ve propiciada, además de por la diferente aproximación ideológica, por la propia evolución del conflicto en el seno de las Naciones Unidas. En efecto, las reticencias que levanta el tema saharaui en el Parlamento Europeo se diluyen cuando las partes en

16. Véase la pregunta formulada por la diputada alemana, Simons, perteneciente al grupo socialista, en EPC Documentation Bull, doc. núm. 86/314.

17. Véase la définición en $D O$ núm. I 99, de 16.4.1988.

18. La III Conferencia de Naciones Unidas sobre el Derecho del Mar, en su resolución III de 30.4.1982, contemplaba los derechos sobre el mar de los pueblos que aún no han alcanzado la plena independencia y establecía que para el ejercicio de los derechos sobre el mar las partes de una controversia de soberanía territorial deberán celebrar consultas previas. Veáse sobre este asunto D. Bardonet; M. Virally (1983). 
conflicto alcanzan un primer acuerdo sobre el plan Pérez de Cuéllar en 1988. Así, en diciembre de 1987 los parlamentarios socialistas y comunistas tuvieron que presentar una propuesta de resolución vacía de significación política, que se ceñía a la denuncia de violación de los derechos humanos, con el fin de lograr el número necesario de votos afirmativos en la Asamblea para sacar la resolución adelante. En cambio, un año después del acuterdo entre Marruecos y Frente Polisario, el PE vota afirmativamente la resolución en la que toma partido por la defensa del pueblo saharaui. Quedará un grupo minoritario de diputados cuya postura es la defensa a ultranza de las tesis marroquíes. Esta minoría de diputados no coincide con ningún grupo parlamentario ni pertenecen todos a la misma nacionalidad. Destacan entre estos defensores de la marroquinidad del Sahara, el diputado del Partido Popular Europeo por Alemania, Otto de Habsburgo, y el francés del Grupo Técnico de Derechas Europeo, Martínez; ambos consideran que el pueblo saharaui no existe, el Sahara es una provincia más de: Marruecos y, por lo tanto, el conflicto es una cuestión de orden interno en la que la CE no debería intervenir. Así, Habsburgo argumenta que "históricamente el Sahara no ha sido nunca un Estado. El pueblo saharaui es una tribu que ha pertenecido la mayor parte del tiempo a Marruecos" (Débats... doc. 3-404, 18.4.1991: 270). Martínez afirmaba durante un debate que lo que Marruecos ha aportado al Sahara es "prosperidad y paz, y que hoy un Estado moderno se ha edificado en las provincias saharauis" (Débats... ídem).

\section{El Parlamento Europeo recurre al dictamen no conforme}

El $\mathrm{PE}$ agota todos los instrumentos de que dispone para influir en el diseńo de la política exterior comunitaria cuando se niega a aprobar los cuartos protocolos financieros con Marruecos en $1992^{19}$. El dictamen no conforme del $\mathrm{PE}$ a la aplicación de dichos protocolos financieros con Marruecos va precedido de una resolución, en la que se insta a la Comisión a no iniciar dicha aplicación "hasta que estos países no cumplan las condiciones anteriormente expuestas en lo que se refiere al respeto de los derechos humanos y a las resoIuciones del Consejo de Seguridad de las Naciones Unidas" ${ }^{20}$. Hay que recordar que el AUE otorga a la Comisión la función de velar para que las políticas exteriores de la CE y las políticas convenidas en el seno de la CPE sean coherentes (artículo 30, párrafo 5).

El dictamen provocó tensiones entre Rabat y Bruselas con la amenaza marroquí de no prorrogar el acuerdo de pesca. Como ha señalado Perrakis, tanto el Consejo como la Comisión deberian tener en cuenta esta nueva capacidad del PE y prever la posible reacción de oposición parlamentaria (Revue..., 1989: 49).

19. Acuerdos que se inscriben en el marco de la Políica Mediterránea Renovada y por los que correspondían a Marruecos un total de 220 millones de ecus. Vease a este respecto Bol. CE $1 / 2-1991$, punto 1.3 .24 .

20. Véase en $D O$ núm. C 39 de 17.2.1992, p. 4. 
Sin embargo, nada había sido previsto, y tanto la Comisión como el Ministerio español de Asuntos Exteriores se vieron obligados a desplegar una contraofensiva diplomática. Así lo explicaba el ministro de Asuntos Exteriores, Fernández Ordóñez, ante el Parlamento español: «la irritación en todos los sectores de Marruecos era muy grande como consecuencia del bloqueo en el Parlamento Europeo del IV Protocolo financiero [... es eso nos obligó a comparecer ante el Consejo de Ministros de Asuntos Exteriores de la Comunidad al que fui personalmente con un documento sobre el Magreb" (Diario..., 458, 21.4.1992, 13480). De esta actividad diplomática a tres bandas surge la idea de ofrecer a Marruecos el "partenariado", un acuerdo de fibre comercio aún más ventajoso. "Lo traté - afirmaba Fernández Ordónez- personalmente con el Rey Hassán y le pareció que era una buena propuesta si es que éramos capaces de Ilevarlo a cabo entre el comisario español que lleva el Mediterráneo, que es Abel Matutes, y yo mismo, que éramos las dos personas que nos habíamos agarrado del brazo en esos momentos dificilísimos [...] creo sinceramente que nos coordinamos muy bien" (Diario de Sesiones, 458, 21.4.1992, 13480).

Si la Comisión da vía libre a la negociación del "partenariado" (Comunicación de la Comisión al Consejo «El futuro de las relaciones entre la Comunidad y el Magreb", 19 de abril de 1992), el Consejo Europeo de Lisboa, por su parte, establece unos principios básicos, entre los cuales el respeto a las resoluciones de Naciones Unidas, como marco general de las relaciones con el Magreb (declaración sobre las relaciones euromagrebíes, junio de 1992). De este modo, los Doce salvan la cara frente a la denuncia del PE, a la vez que crea un marco propicio para iniciar la negociación de los acuerdos de "partenariadon con Marruecos. Actitud que el diputado italiano del grupo de los Verdes, Melandri, no dudó en calificar de maniobra del Consejo Europeo que pretende crear una cortina de humo para no tomar en consideración la opinión del Parlamento ${ }^{21}$.

\section{Conclusiones}

La actuación del Parlamento Europeo puede calificarse de reacción tardía, marcada por un factor determinante: la adhesión española. En efecto, el PE en 1981 se pronunció a favor de las tesis marroquíes sostenidas en esos momentos por Francia. Sólo a partir de 1986, la cuestión saharaui empieza a ser un tema a tratar en una asamblea que evolucionará paulatinamente hacia la defensa del derecho de autodeterminación del pueblo saharaui. Para, finalmente, en 1989, adoptar una resolución de carácter político en este sentido. Si antes de 1986, las voces que se elevaban en Estrasburgo en favor del pueblo saharaui estaban aisladas, la situación cambia con la entrada de parlamentarios españoles y la creación del intergrupo "Paz para el pueblo saharaui». Los parlamentarios españoles han contribuido a la política del gobierno español de

21. Véase la exposición del diputado en Debats du Parlement Européen, núm. 3-416, de 11.3.1992, p. 138-139. 
"europeizar» los temas de la política exterior española introduciéndo el Sahara Occidental en la agenda del Parlamento Europeo.

La evolución del PE se explica también por la distinta percepción del conflicto que poseen los parlamentarios según su adscripción ideológica. Los grupos de la izquierda demuestran un mayor interés e identificación con el problema saharaui. De hecho, de sus filas provienen las 29 preguntas realizadas en el PE sobre el tema, la mayoría de las propuestas de resolución (observándose un aumento de la participación de otros grupos con los años) y las intervenciones en los debates sobre el Sahara Occidental. Los partidos de la derecha actúan por omisión; así, tan sólo una propuesta de resolución proviene del PPE (presentada por un diputado espańol).

$\mathrm{La}$ postura del $\mathrm{PE}$, expresada en forma de resoluciones y de preguntas a los ministros de Asuntos Exteriores en el marco CPE, no debe considerarse marginal. Partíamos de la hipótesis, determinada por la debilidad constitutiva del PE, de que tendría un papel meramente simbólico en la definición de dicha política. La hipótesis se ha confirmado en lo que respecta a la incidencia directa en el proceso comunitario de toma de decisión. Sin embargo, gracias a las resoluciones, a las preguntas y a los informes elaborados por las comisiones, el Parlamento Europeo ejerce una labor de denuncia y reivindicación no desdeñable.

Así, cuando el Parlamento Europeo decide utilizar del dictamen no conforme en el caso de los cuartos protocolos financieros con Marruecos en 1992, se produce una tensión en las relaciones CE-Marruecos que provoca un tour de force entre las instituciones comunitarias. La Comisión y el Consejo se ven obligadas a poner en marcha mecanismos para contrarrestar los efectos de la negativa del Parlamento. Además, el Parlamento Europeo, con su actitud pone en evidencia a la Comisión y al Consejo que se niegan a vincular las cuestiones del ámbito comunitario (relaciones Marruecos-CE, tratado de pesca) y las de la cooperación política (declaración común de los Doce sobre el Sáhara Occidental) en contra de lo estipulado en el Acta Única Europea. Tanto la Comisión como los ministros reunidos en el marco de la cooperación política, se amparan en la división de ambos marcos cuando el Parlamento, sea mediante preguntas sea mediante resoluciones, subraya dichas incoherencias.

\section{Bibliografía}

\section{Libros y Revistas}

BARDONET, D.; VIRALly, M. (1983). Le nouveau Droit International de la Mer, París: Pedone.

COVILIERs, C. (1989). Y a t'il une politique extérieure des Communautés Européennes? París: PUF.

ChaUCHAT, M. (1989). Le contrôle politique du Parlement Europlen sur les exxecutifs communautaires. París: Bibliothèque de Droit International, núm. 98.

FroberVILlE, M. DE (1992). «Sahara Occidental: échec au plan de paixm. Le Monde Diplomatique, p. 13. 
KEESING's, Keessing's Contemporary Archives: Weekly Diary of World Events, Keesing. LESCAUT, Ch. (1988). «Sahara Occidental». L'etat des conflits dans le monde.

Moran, F. (1984), «Principios de la política exterior española" Leviatán, núm. 16, p. 7-20.

OSTERUD, O.(1989). "War termination in the Western Sahara», Bulletin of Peace Proposal vol. 20, núm. 3, p. 309-317.

PERRAKIS, S. (1989). «Les relations extérieures de la Communauté Européenne aptès l'Acte Unique Européen». Revue du Marché Comun, núm. 30, p. 488-495.

SCHOUTHEETE, P.(1980). La coopération politique européenne. Bruselas: Labor.

SOUDAN, F. (1988). «Les secrets (et les limites) d'une réconciliation». Jeune Afrique, núm. 1429, p. 18-19.

TAMAMES, R. (1994). La Union Europea. Madrid: Alianza Edirorial.

WEILER, J.; PETRY, F.(1982). The European Parliament and its foreign affairs committees. Nueva York: Oceana Publications INC.

\section{Documentos y publicaciones oficiales}

Diario Oficial de la Comunidad Europea.

Boletín de la CEE.

CPE. European Political Cooperation Documentation Bufletin. European University Institute. Florence.

Developpement. «La Pêche dans les pays en voie de developpement. La politique de la CEm, octubre de 1990.

- "Europe er le Grand Maghreb" D.E. 68, enero de 1991.

Diario de Sesiones del Parlamento Europeo.

Ecos de la Sesión del Parlamento Europeo.

Débats dı Parlement Europén.

Manuel Officiel du Parlement Européen, 1984.

Vademecum, Parlamento Europeo, 1987.

Dossiers de Recherche. "L'impact du Parlement Européen sur les politiques Communautaires", Serie 3/11-1988. 